\title{
Computational design of highly stable and soluble alcohol dehydrogenase for NADPH regeneration
}

\author{
Jinling $X u^{1}$, Haisheng Zhou ${ }^{2 *}$, Haoran $Y u^{1,2}$, Tong Deng ${ }^{1}$, Ziyuan Wang ${ }^{1}$, Hongyu Zhang ${ }^{1,2}$, Jianping Wu ${ }^{1,2}$ \\ and Lirong Yang ${ }^{1,2^{*}}$
}

\begin{abstract}
Nicotinamide adenine dinucleotide phosphate (NADPH), as a well-known cofactor, is widely used in the most of enzymatic redox reactions, playing an important role in industrial catalysis. However, the absence of a comparable method for efficient $\mathrm{NADP}^{+}$to NADPH cofactor regeneration radically impairs efficient green chemical synthesis. Alcohol dehydrogenase (ADH) enzymes, allowing the in situ regeneration of the redox cofactor NADPH with high specific activity and easy by-product separation process, are provided with great industrial application potential and research attention. Accordingly, herein a $\mathrm{NADP}^{+}$-specific $\mathrm{ADH}$ from Clostridium beijerinckii was selected to be engineered for cofactor recycle, using an automated algorithm named Protein Repair One-stop Shop (PROSS). The mutant CbADH-6M (S24P/G182A/G196A/H222D/S250E/S254R) exhibited a favorable soluble and highly active expression with an activity of $46.3 \mathrm{U} / \mathrm{mL}$, which was 16 times higher than the wild type $(2.9 \mathrm{U} / \mathrm{mL})$, and a more stable protein conformation with an enhanced thermal stability: $\Delta T_{1 / 2}^{60 \mathrm{~min}}=+3.6^{\circ} \mathrm{C}$ (temperature of $50 \%$ inactivation after incubation for $60 \mathrm{~min}$ ). Furthermore, the activity of $\mathrm{CbADH}-6 \mathrm{M}$ was up-graded to $2401.8 \mathrm{U} / \mathrm{mL}$ by high cell density fermentation strategy using recombinant Escherichia coli, demonstrating its industrial potential. Finally, the superb efficiency for NADPH regeneration of the mutant enzyme was testified in the synthesis of some fine chiral aromatic alcohols coupling with another ADH from Lactobacillus kefir (LkADH).
\end{abstract}

Keywords: Alcohol dehydrogenase, Computational design, Soluble expression, NADPH regeneration, Chiral alcohols

\section{Introduction}

The ability of enzymes to operate simply in aqueous systems in a highly efficient manner makes them attractive environmentally benign synthetic reagents. However, many biocatalysts have not been fully exploited in industry, and their use in the large-scale enzymatic synthesis of high added-value chemicals is often limited by expensive cofactors. Typical cofactor dependent enzymes are oxidoreductases representing around $25 \%$ of all known enzymes (Liu and Wang 2007), which catalyzes about

\footnotetext{
*Correspondence: hs-zhou@zju.edu.cn; Iryang@zju.edu.cn ${ }^{1}$ Institute of Bioengineering, College of Chemical and Biological Engineering, Zhejiang University, Hangzhou 310027, China

2 Hangzhou Global Scientific and Technological Innovation Center, Zhejiang University, Hangzhou 310027, China
}

$30 \%$ of the biotransformations in industry (Straathof et al. 2002), and the vast majority are dependent on two nicotinamide cofactors NADH or NADPH. Although these two cofactors differ only by the $2^{\prime}$-phosphate group that is attached to the adenine ribose in NADPH, they play a completely different role in nature. NADH is used almost exclusively for oxidative degradations that eventually lead to production of ATP, whereas NADPH is confined with few exceptions to the biosynthetic reactions (Carugo and Argos 1997), involving a spectrum of over 300 known, repeatedly used reaction types (Woodyer et al. 2005), e.g., C-H oxygenation (Landwehr et al. 2006), regioselective halogenation (Mori et al. 2019), Baeyer-Villiger oxidation (Schmidt et al. 2015), stereoselective reduction (Zhu and Hua 2006) and reductive amination (Yin et al. 
2020) (Fig. 1). Therefore, it is necessary to develop an efficiently applicable technique for the in situ regeneration of NADPH to fulfill "green" chemical synthesis.

Currently, numerous chemical, electrochemical, photochemical and biochemical methods have been developed to regenerate NADPH (Brown et al. 2016; Fukuzumi et al. 2019; Wichmann and Vasic-Racki 2005). Most chemical routes are hindered by cumbersome reaction conditions, low turnover number (TTN), expensive and/or toxic reagents, and/or unwanted side products, therefore not preferred for commercial or preparative applications. Biochemical methods with enzymes as catalysts have been demonstrated more efficient and applicable (Huisman et al. 2010), including the use of glucose dehydrogenase (GDH) (Weckbecker and Hummel 2005), glucose-6-phosphate dehydrogenase (G6PDH) (Zhang et al. 2006), alcohol dehydrogenase (ADH) (Bastos et al. 1999), phosphite dehydrogenase (PDH) (Johannes et al. 2007a), formate dehydrogenase (FDH) (Celik et al. 2014), hydrogenase (Fan et al. 2020) and so forth. GDH and G6PDH with an advantage of high specific activity (200$500 \mathrm{U} / \mathrm{mg}$ at $25-30^{\circ} \mathrm{C}$ ) (Ding et al. 2011; Wennekes et al. 1993) suffer from high co-substrate consumption and by-product separation cost. By contrast, PDH and FDH using cheap co-substrate to regenerate NADPH without by-product problem, possess very low specific activity (FDH, $5-20 \mathrm{U} / \mathrm{mg}$ at $25-30{ }^{\circ} \mathrm{C} ; \mathrm{PDH}, 5 \mathrm{U} / \mathrm{mg}$ at $25{ }^{\circ} \mathrm{C}$ ) (Vázquez-Figueroa et al. 2007). Additionally, because of significantly low stability and activity, the biotechnological applications of hydrogenases are still in their infancy (Fan et al. 2020). Nevertheless, ADH with a comparable specific activity $\left(140-170 \mathrm{U} / \mathrm{mg}\right.$ at $25-40{ }^{\circ} \mathrm{C}$ ) (Peretz et al. 1997; Widdel and Wolfe 1989) and easy by-product separation process when using isopropanol as cheap $\mathrm{H}$-donor (Fig. 1), is of considerable commercial value as a catalyst for NADPH regeneration in the synthesis and/or biotransformation of valuable compounds.

However, NADPH-dependent ADHs have been widely applied to the synthesis of chiral alcohols and few studies applied the ADH for NADPH coenzyme recycle (Benítez-Mateos et al. 2017; He et al. 2015; Itoh 2014). Although some ADHs can catalyze the synthesis of product and the regeneration of cofactor simultaneously in a substrate-coupled system, the two substrates could be competitively inhibited by each other, which decreased the production of the target products. Moreover, advanced enzyme engineering technologies have been used to improve some ADH performances including substrate specificity, enantioselectivity and catalytic activity. However, the NADPH regenerating ADHs have not been explored.

Here an ADH from Clostridium beijerinckii (CbADH) was identified with excellent thermostability and high specific activity for NADPH regeneration. In order to improve the poor heterologous expression level of $\mathrm{CbADH}$ (Peretz et al. 1997), an automated structure- and sequence-based computational protein redesign method named Protein Repair One-Stop Shop (PROSS) (Goldenzweig et al. 2016), was applied to engineer wild-type $\mathrm{CbADH}$ to obtain improved mutants that could satisfy laboratory and even industrial applications. Furthermore, a two-phase high cell density fermentation strategy was explored to the large-scale production of the best mutant to demonstrate its industrial potential. Also, the performance of the obtained variant was verified at in situ NADPH regeneration in the synthesis of some

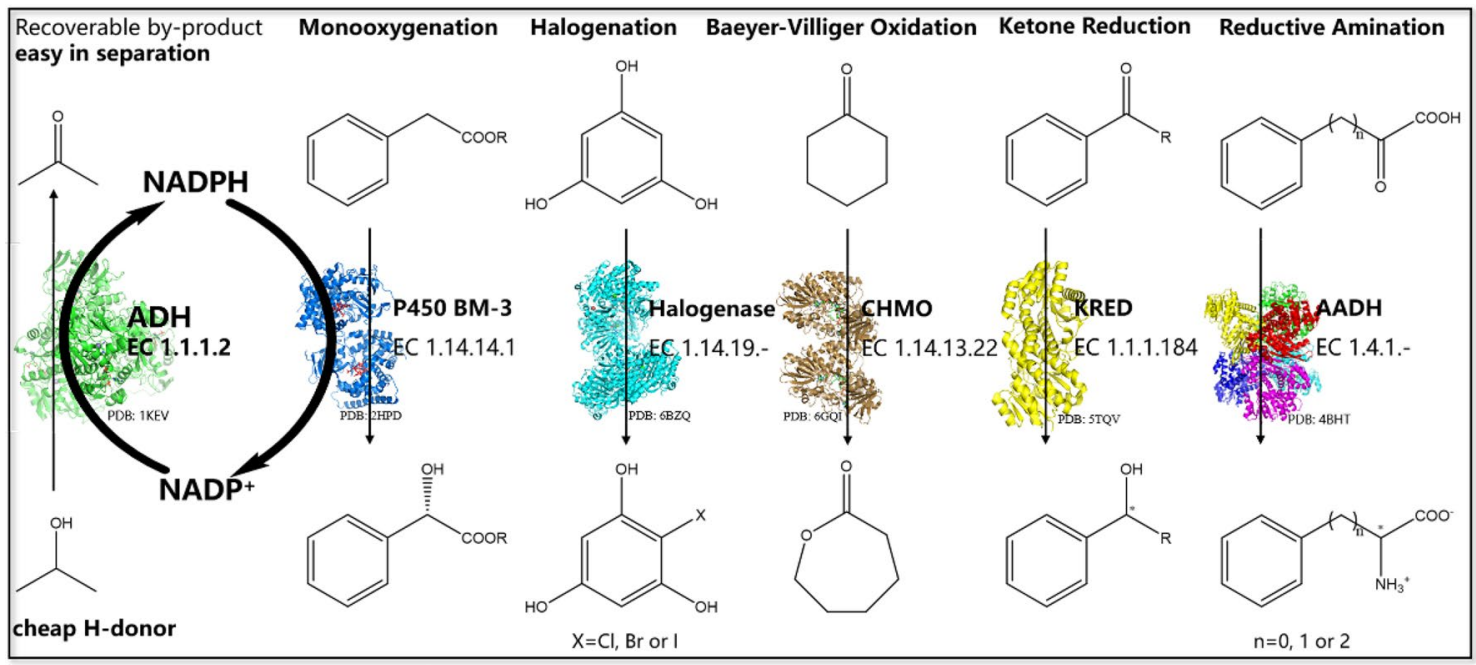

Fig. 1 Biosynthetic reactions using NADPH 
fine chiral aromatic alcohols coupling with another engineered ADH from Lactobacillus kefir (LkADH) (He et al. 2015).

\section{Materials and methods}

\section{Microorganisms and plasmids}

An in-house E. coli BL21 (DE3) was used as a host bacteria for recombinant expression The plasmid pET-28a (with $\mathrm{N}$-terminal His-tag fused) carrying the TgADH, $\mathrm{CbADH}, \mathrm{TbADH}, \mathrm{TeADH}, \mathrm{EhADH}$ and LkADH gene were prepared by Beijing Tsingke Biological Technology Company, who also carried out the primer synthesis and sequencing.

\section{Culture and induction conditions}

The recombinant E. coli cells were first cultured for $6-8 \mathrm{~h}$ at $37{ }^{\circ} \mathrm{C}$ in $5 \mathrm{~mL}$ Luria-Bertani (LB) medium supplemented with $50 \mu \mathrm{g} / \mathrm{mL}$ kanamycin sulfate, which were then transformed into flask $(50 \mathrm{~mL} \mathrm{LB})$ at $37^{\circ} \mathrm{C}$ with rotary shaking at $200 \mathrm{rpm}$ until the $\mathrm{OD}_{600}$ reached 0.4-0.6. Cells were induced at the specific temperature $\left(16-30{ }^{\circ} \mathrm{C}\right)$ for $16 \mathrm{~h}$ by addition of isopropyl- $\beta$-Dthiogalactopyranoside (IPTG, 0.1-1.0 mM).

\section{Construction of PROSS mutants}

The CbADH-related parameters and protein crystal structure were submitted online on a dedicated web server (http://PROSS.weizmann.ac.il). The recombinant plasmid pET-28a-CbADH containing the $\mathrm{CbADH}$ mutants were constructed through whole gene synthesis, and expressed in E. coli BL21. All sequences were verified by DNA sequencing at Beijing Tsingke biological technology Co. Ltd.

\section{Enzyme assay}

The induced cells were harvested by centrifugation and washed three times using deionized water. Finally, the harvested cells were resuspended in $100 \mathrm{mM}$ phosphate buffer ( $\mathrm{pH}$ 7.5) and disrupted ultrasonically. The obtained suspension was diluted for enzyme assay. The standard assay mixture $(1 \mathrm{~mL})$ consisted of $100 \mathrm{mM}$ phosphate buffer ( $\mathrm{pH}$ 7.5), $50 \mathrm{mM}$ isopropyl alcohol, $1 \mathrm{mM}$ $\mathrm{NADP}^{+}$, and enzyme. The substrate and coenzyme solution were incubated in a metal bath at $35^{\circ} \mathrm{C}$ and $650 \mathrm{rpm}$ for $10 \mathrm{~min}$. Once the enzyme solution was added, the reaction solution was scanned at $340 \mathrm{~nm}$ by spectrophotometer for $60 \mathrm{~s}$, and the change in absorbance was recorded to calculate the enzyme activity. One unit of enzyme activity was defined as the amount of enzyme required to catalyze the formation of $1 \mu \mathrm{mol}$ NADPH per minute.

\section{SDS-PAGE and protein concentration assays}

The expression and purification of the recombinant ADHs were analyzed by sodium dodecyl sulfate-polyacrylamide gel electrophoresis (SDS-PAGE, 12\%) with a 5\% stacking gel. The gels were stained with Coomassie Brilliant Blue G-250. Protein concentrations were determined using a Bradford protein assay kit (Quick Start $^{\mathrm{TM}}$, Bio-Rad, USA).

\section{Purification of recombinant protein}

The collected cells were washed and resuspended in $\mathrm{Ni}-0$-native buffer (20 mM sodium phosphate, $\mathrm{pH} 7.5$, containing $500 \mathrm{mM} \mathrm{NaCl}$ ). Resuspended cells were disrupted by ultrasonication in an ice bath, followed by centrifugation at $12,000 \mathrm{~g}$ for $30 \mathrm{~min}$ to discard cell debris. The supernatant was loaded onto a Ni-NTA column (Thermo Scientific, USA) pre-equilibrated with $\mathrm{Ni}$-0-native buffer, and the proteins were eluted by an increasing gradient of imidazole (from 50 to $250 \mathrm{mM}$ ). The purities of the collected fractions were analyzed by SDS-PAGE. Fractions containing the pure target protein were gathered and desalted by ultrafiltration. The purified proteins were concentrated and stored in $20 \%$ (v/v) glycerol at $-80^{\circ} \mathrm{C}$ until further use.

\section{Characterization of enzymatic properties}

Temperature and $\mathrm{pH}$ dependence: the temperature dependence was determined over the range $15-75^{\circ} \mathrm{C}$. The mixture except the enzyme was preincubated for $10 \mathrm{~min}$ at a serious of temperature, and the reaction was initiated by the addition of enzyme solution preincubated for $10 \mathrm{~min}$ at the same temperature. The optimum $\mathrm{pH}$ was determined at $35^{\circ} \mathrm{C}$ using different buffer systems to cover the $\mathrm{pH}$ scale: $100 \mathrm{mM}$ phosphate buffer ( $\mathrm{pH}$ 6.0-7.5); $100 \mathrm{mM}$ Tris- $\mathrm{HCl}$ buffer $(\mathrm{pH}$ 7.5-9.0); $100 \mathrm{mM}$ glycine- $\mathrm{NaOH}$ buffer (pH 9.5-11.0); $100 \mathrm{Mm} \mathrm{Na}_{2} \mathrm{HPO}_{4}$ buffer (pH 11.0-13.0).

$\mathrm{pH}$ stability: the $\mathrm{pH}$ stability was measured by incubation of purified enzyme in buffer $(\mathrm{pH} \mathrm{6-10)}$ for $24 \mathrm{~h}$ 
at $35^{\circ} \mathrm{C}$, and the residual activity was then measured by standard assay.

Thermal stability: the thermal stability was characterized by $T_{1 / 2}^{60 \mathrm{~min}}$ (temperature of $50 \%$ inactivation after incubation for $60 \mathrm{~min}$ ) and half-life. $T_{1 / 2}^{60 \mathrm{~min}}$ was measured at different temperature where the enzyme activity is reduced to $50 \%$ of its initial activity after incubation for $60 \mathrm{~min}$. The half-life $\left(t_{1 / 2}\right)$ was defined as the time when the residual activity retained $50 \%$ of its original activity at the measured temperature. The diluted purified $\mathrm{CbADH}$ solution $(1.0 \mu \mathrm{g} / \mathrm{mL})$ was preincubated at $50,60,70{ }^{\circ} \mathrm{C}$ for different durations. The residual enzyme activity was then measured under standard conditions.

\section{High-density fermentation}

Single colonies were selected from the plate and incubated in $50 \mathrm{~mL} \mathrm{LB}$ medium for primary seeds, and cultured overnight at $37{ }^{\circ} \mathrm{C}, 200 \mathrm{rpm}$. The cells were then transferred to $500 \mathrm{~mL} \mathrm{LB}$ medium for secondary seeds and cultured at $200 \mathrm{rpm}, 37^{\circ} \mathrm{C}$ for $4 \mathrm{~h}$. The secondary seed culture solution was transferred to a $15.0-\mathrm{L}$ fermentation tank under aseptic conditions, cultured in a 7.0-L fermentation medium (15.0 g/L glycerol; $25.0 \mathrm{~g} / \mathrm{L}$ yeast extract (Xiwang, China); $17.1 \mathrm{~g} / \mathrm{L} \mathrm{Na}_{2} \mathrm{HPO}_{4} \cdot 12 \mathrm{H}_{2} \mathrm{O}$; $3.0 \mathrm{~g} / \mathrm{L} \mathrm{KH} \mathrm{KH}_{2} \mathrm{PO} ; 1.0 \mathrm{~g} / \mathrm{L} \mathrm{NaCl} ; 1.0 \mathrm{~g} / \mathrm{L} \mathrm{NH}_{4} \mathrm{Cl} ; 1.3 \mathrm{~g} / \mathrm{L}$ $\mathrm{MgSO}_{4} \cdot 7 \mathrm{H}_{2} \mathrm{O} ; 0.3 \mathrm{~g} / \mathrm{L} \mathrm{ZnSO}_{4} \cdot 7 \mathrm{H}_{2} \mathrm{O}$; and $0.05 \mathrm{~g} / \mathrm{L}$ kanamycin sulfate;) at $37{ }^{\circ} \mathrm{C}$. When the glycerol of the fermentation medium was depleted, the feeding medium (400.0 g/L glycerol; $100.0 \mathrm{~g} / \mathrm{L}$ yeast extract) was started. To avoid the accumulation of glycerol in the broth, the feeding medium was added using a continuous model by monitoring the changes in the DO (dissolved oxygen) level, $\mathrm{pH}$ value and glycerol concentration during fermentation. The tank was cooled to $22{ }^{\circ} \mathrm{C}$ for induction until the cell density $\left(\mathrm{OD}_{600}\right)$ reached $70-90$. The $\mathrm{pH}$ was controlled at 7.0 through the adjustment of ammonia, additionally the dissolved oxygen was controlled at about $30 \%$.

\section{HPLC analysis and detection}

The conversion of ketones and the enantiomeric excess of chiral alcohol products were detected with a normalphase chiral column (CHIRAL PAK, ZWIX(-), $3 \mu \mathrm{m}$, $4 \times 150 \mathrm{~mm}$ ) using a FL-2200 HPLC system (Fuli Analytical Instrument Co., Ltd., China). The flow rate was maintained at $0.6 \mathrm{~mL} / \mathrm{min}$, with detection at $230 \mathrm{~nm}$, and the column temperature was constant at $25{ }^{\circ} \mathrm{C}$, applying isocratic elution of $n$-hexane/isopropanol/trichloroacetic $\operatorname{acid}(90 / 10 / 0.1, \mathrm{v} / \mathrm{v} / \mathrm{v})$.
Preparative applications of ADHs for the synthesis of chiral alcohols

Reactions were carried out at $35{ }^{\circ} \mathrm{C}$ by magnetic agitation with $100 \mathrm{mM}$ phosphate buffer $(\mathrm{pH} 7.5)$ as the medium $(50 \mathrm{~mL})$. Each reaction sample contained $50 \mathrm{mM}$ precursor ketone, $60 \mathrm{mM}$ isopropanol, $0.1 \mathrm{mM}$ $\mathrm{NADP}^{+}, 1.0$ gdcw L ${ }^{-1}$ LkADH cells for LkADH monoenzymatic reaction or $0.95 \mathrm{gdcw} \mathrm{L}^{-1} \mathrm{LkADH}$ cells plus 0.05 gdcw $\mathrm{L}^{-1} \mathrm{CbADH}-6 \mathrm{M}$ cells for dual enzyme catalyzed reaction. The recombinant LkADH and CbADH$6 \mathrm{M}$ cells were resuspended in $100 \mathrm{mM}$ phosphate buffer (pH 7.5) and disrupted ultrasonically. The resultant slurry was centrifuged at $12,000 \mathrm{~g}$ and the supernatant was used for the redox reaction. The reaction process was monitored by the determination of residual substrate concentration using HPLC, as described in the "HPLC analysis and detection" section.

\section{Results and discussion \\ Alcohol dehydrogenase library construction and activity identification}

NADPH-specific ADH (EC 1.1.1.2) from different sources have been reported a lot according to the enzyme database BRENDA. However, few of them have high activity. Here, an ADH library containing $\mathrm{CbADH}$ with specific activity exceeding about $10 \mathrm{U} / \mathrm{mg}$ was constructed (Additional file 1: Table S1). However, some of them were not suitable for NADPH regeneration as they only oxidized primary alcohols and produced aldehydes which inactivated enzymes. Hence, those showing activity towards secondary alcohols were selected for further investigation. Soluble expression levels and NADPH regenerating activities (per volume of fermentation broth) were tested for these secondary ADHs with an exception of MtADH (Additional file 1: Fig. S1), which uses unavailable $\mathrm{F}_{420}$ as a cofactor (Widdel and Wolfe 1989). All the other six enzymes were successfully expressed in $E$. coli (Additional file 1: Fig. S2) and considerable activities of TgADH, CbADH, TbADH and LkADH were obtained (Fig. 2a). Among them, TgADH exhibited a highest activity but a limited stability in atmosphere, meanwhile LkADH was also demonstrated to be less stable than $\mathrm{CbADH}$ (Fig. 2b). CbADH showed the second highest activity $(2.9 \mathrm{U} / \mathrm{mL})$ with a soluble enzyme protein ratio of $25.1 \%$, which was the lowest and less than a quarter of $\mathrm{TbADH}(96.9 \%)$, indicating that the specific activity of $\mathrm{CbADH}$ was supreme. Subsequently, the recombinant $\mathrm{CbADH}$ was purified to electrophoretic purity with an activity of $169 \pm 2.3 \mathrm{U} / \mathrm{mg}$. Considering its high specific activity and stability, $\mathrm{CbADH}$ was selected for NADPH 

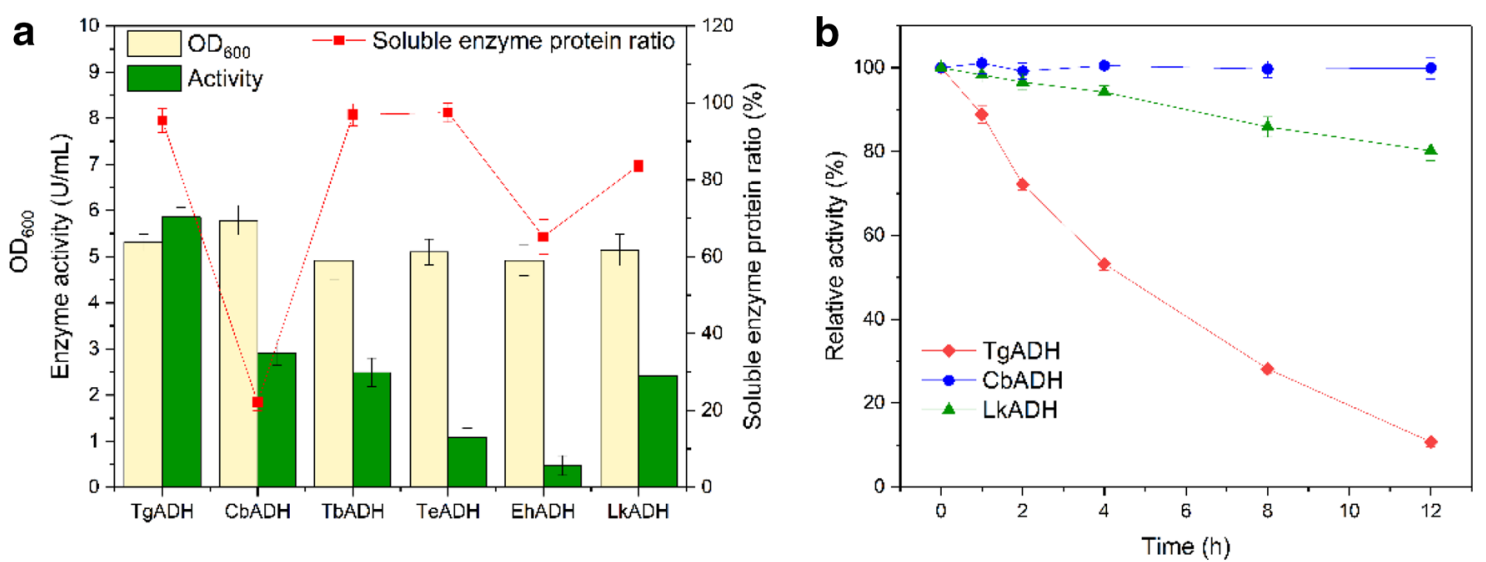

Fig. 2 Characterization of alcohol dehydrogenases. a Enzyme activity and soluble expression of alcohol dehydrogenases in shake-flask fermentation at $25^{\circ} \mathrm{C}$ with $0.5 \mathrm{mM}$ IPTG dosage. b Stability of the crude extract enzymes in atmosphere at $25^{\circ} \mathrm{C}$
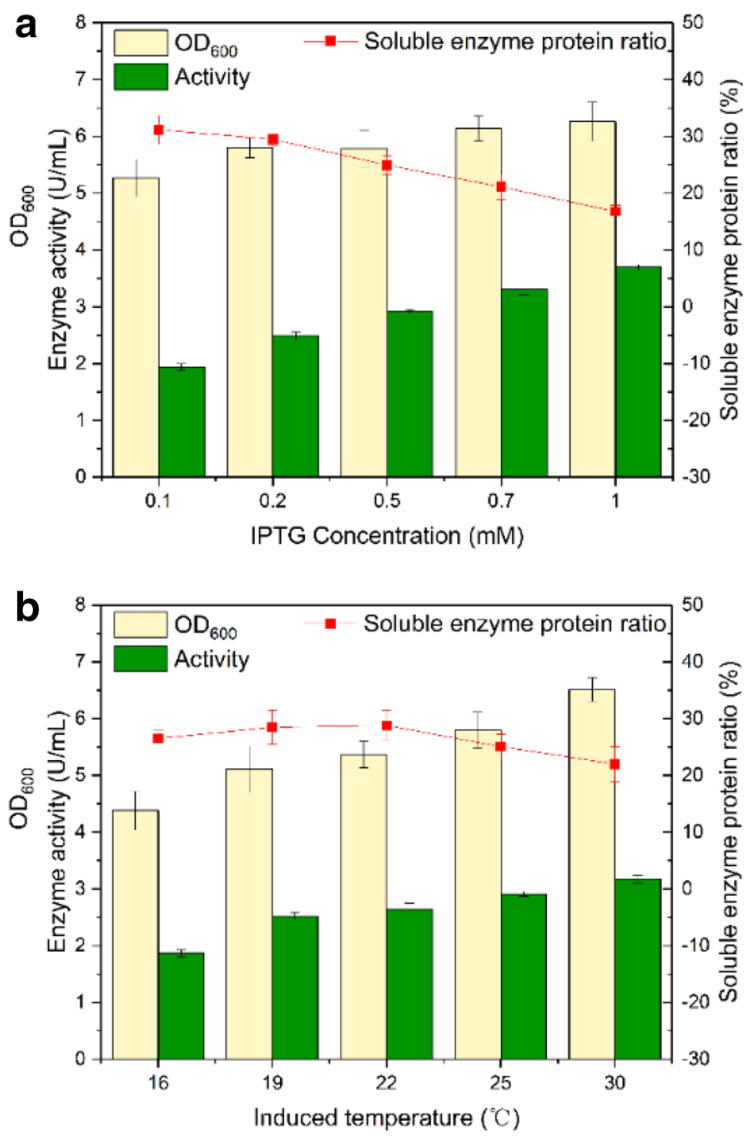

Fig. 3 Effects of induction conditions on the wild CbADH activity in shake-flask fermentation. a Induced by different IPTG concentrations $(0.1-1.0 \mathrm{mM})$ at $25^{\circ} \mathrm{C}$. $\mathbf{b}$ Induced at different temperatures $\left(16-30{ }^{\circ} \mathrm{C}\right)$ with $0.5 \mathrm{mM}$ IPTG dosage regeneration, despite that the heterogenous expression of $\mathrm{CbADH}$ was urgently needed to be improved.

\section{Culturing conditions optimization for $\mathrm{CbADH}$ expression}

The most conventional and simple method to improve the heterogenous protein expression is to balance the target protein biosynthesis and the cell growth by optimizing the induction temperature and the concentration of the inducer IPTG (Donovan et al. 1996). However, the effect of this culture condition optimization strategy on the expression of $\mathrm{CbADH}$ was not significant. With the increase of IPTG concentration, the total enzyme activity increased slightly, but the proportion of soluble enzyme protein decreased (Fig. 3a and Additional file 1: Fig. S4). Additionally, the induction temperature had little influence on the activity and soluble enzyme-protein ratio (Fig. 3b and Additional file 1: Fig. S3). The maximum enzyme activity was only $3.7 \mathrm{U} / \mathrm{mL}$ with the lowest soluble target protein ratio of $16.8 \%$, achieved at induction temperature $25^{\circ} \mathrm{C}$ and IPTG concentration of $1 \mathrm{mM}$.

\section{Improving $\mathrm{CbADH}$ solubility by chaperone buffering}

Chaperone-assisted protein folding was another frequently used approach to overcome the problem of low soluble expression in overexpression systems (Balbás 2001). Therefore, five commercial chaperones were coexpressed with $\mathrm{CbADH}$, respectively, and the results showed that strain A co-expressed with GroEL/ES preferably improved the soluble expression of $\mathrm{CbADH}$ with an activity of $14.1 \mathrm{U} / \mathrm{mL}$ and a soluble target protein ratio of about 59.6\% (Additional file 1: Fig. S5, 6). Subsequently, 
the chaperone co-expression was optimized and the results were shown in another of our work (Deng et al. 2020). However, the expression of chaperone protein will occupy the resources of cells for expressing target enzyme protein, as a result, the target enzyme activity could not reach the theoretical maximum.

\section{Computational protein redesign for enhancing $\mathrm{CbADH}$ solubility}

The gap between the high specific activity versus the extremely low expressional activity becomes a major obstacle to the industrial application of $\mathrm{CbADH}$. Directed evolution and computational redesign of natural enzymes have proven capable of bridging equally large gaps (Musil et al. 2018). Previous studies have used sitedirected mutagenesis to improve the stability of $\mathrm{CbADH}$ (Bogin et al. 2002; Goihberg et al. 2007), but neglected its soluble expression. Unfortunately, stability enhancements often come at the cost of reduced enzyme activity. The computational protein redesign tools provided another method to avoid this trade-off and also to solubilize the polypeptides, facilitating the purposeful adaptation of natural enzymes. Among them, Protein Repair One-Stop Shop (PROSS), an automated web-based protein stabilization platform was proven efficient by the soluble expression of several human proteins in bacteria with unmodified function (Goldenzweig et al. 2016). Here, the PROSS was applied to redesign $\mathrm{CbADH}$. Functionally relevant key sites, including $\mathrm{Zn}^{2+}$ and cofactor ligand binding sites, and dimer interface sites were excluded from mutation (Additional file 1: Fig. S7, Table S3). After three rounds of online calculations, five random mutations were selected for experimental verification. Synthetic genes encoding wild-type CbADH (CbADH-WT) and the five designs were expressed in E. coli BL21 (DE3), and the results showed that mutations except $\mathrm{CbADH}-$ $24 \mathrm{M}$ were expressed with higher solubility and activity than the wild-type $\mathrm{CbADH}$, and the soluble enzyme protein ratio and activity dramatically decreased with the number of mutation sites increased (Fig. 4a and Additional file 1: Fig. S8), that was different from Goldenzweig's work. In addition, thermal stabilities of three mutations, CbADH-6M $\left(T_{1 / 2}^{60 m i n}=66.8^{\circ} \mathrm{C}\right), \mathrm{CbADH}-10 \mathrm{M}$ $\left(T_{1 / 2}^{60 \min }=64.9{ }^{\circ} \mathrm{C}\right)$ and $\mathrm{CbADH}-14 \mathrm{M}\left(T_{1 / 2}^{60 \min }=67.3{ }^{\circ} \mathrm{C}\right)$ were significantly improved compared with the wildtype enzyme $\left(T_{1 / 2}^{60 \mathrm{~min}}=63.7^{\circ} \mathrm{C}\right)$ (Fig. $\left.4 \mathrm{~b}\right)$. The best variant $\mathrm{CbADH}-6 \mathrm{M}$ was tested to have an expressional activity of $46.3 \mathrm{U} / \mathrm{mL}$ and a soluble enzyme protein ratio of $82.4 \%$, which were 16 -fold and threefold higher than the

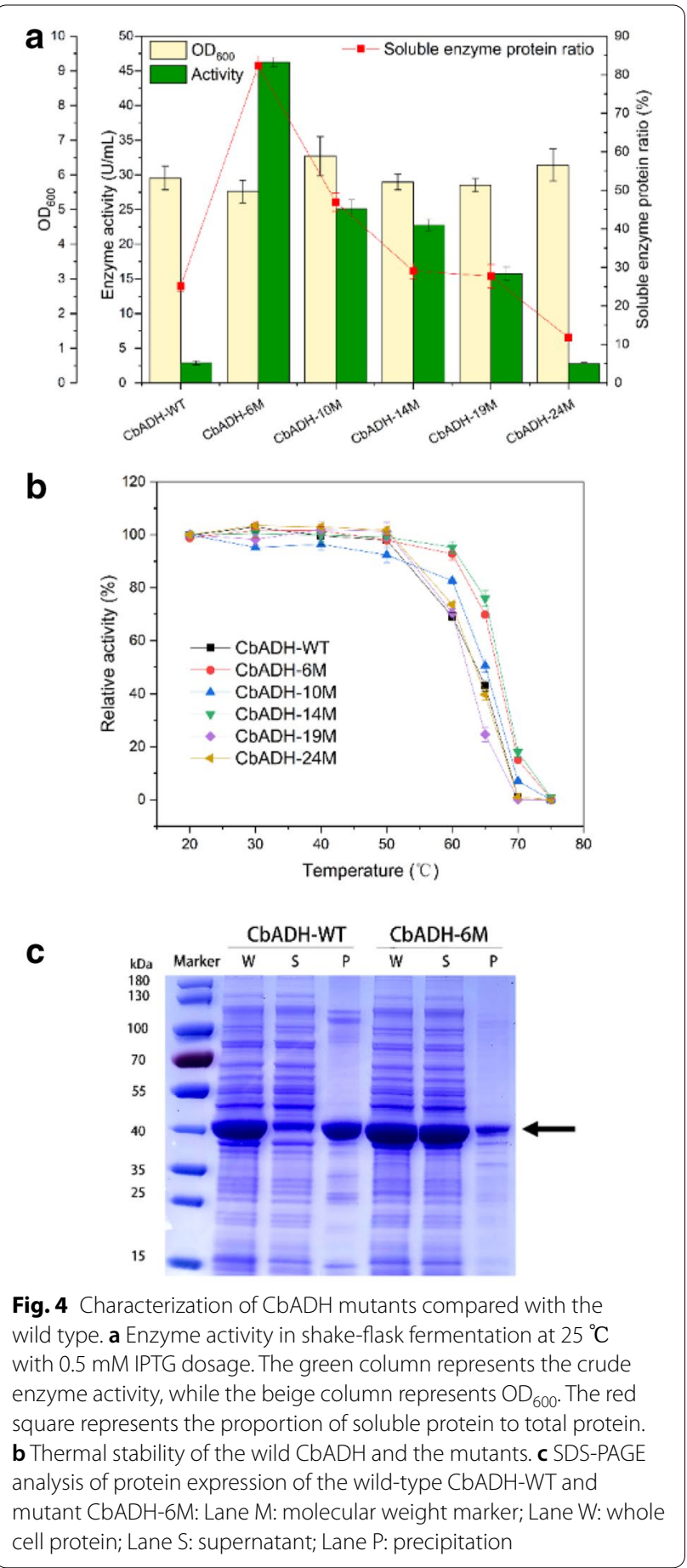

wild type, respectively (Fig. 4c). Although completely soluble expression was not achieved by sequence redesign of $\mathrm{CbADH}, \mathrm{PROSS}$ has been proved to be a simple and 


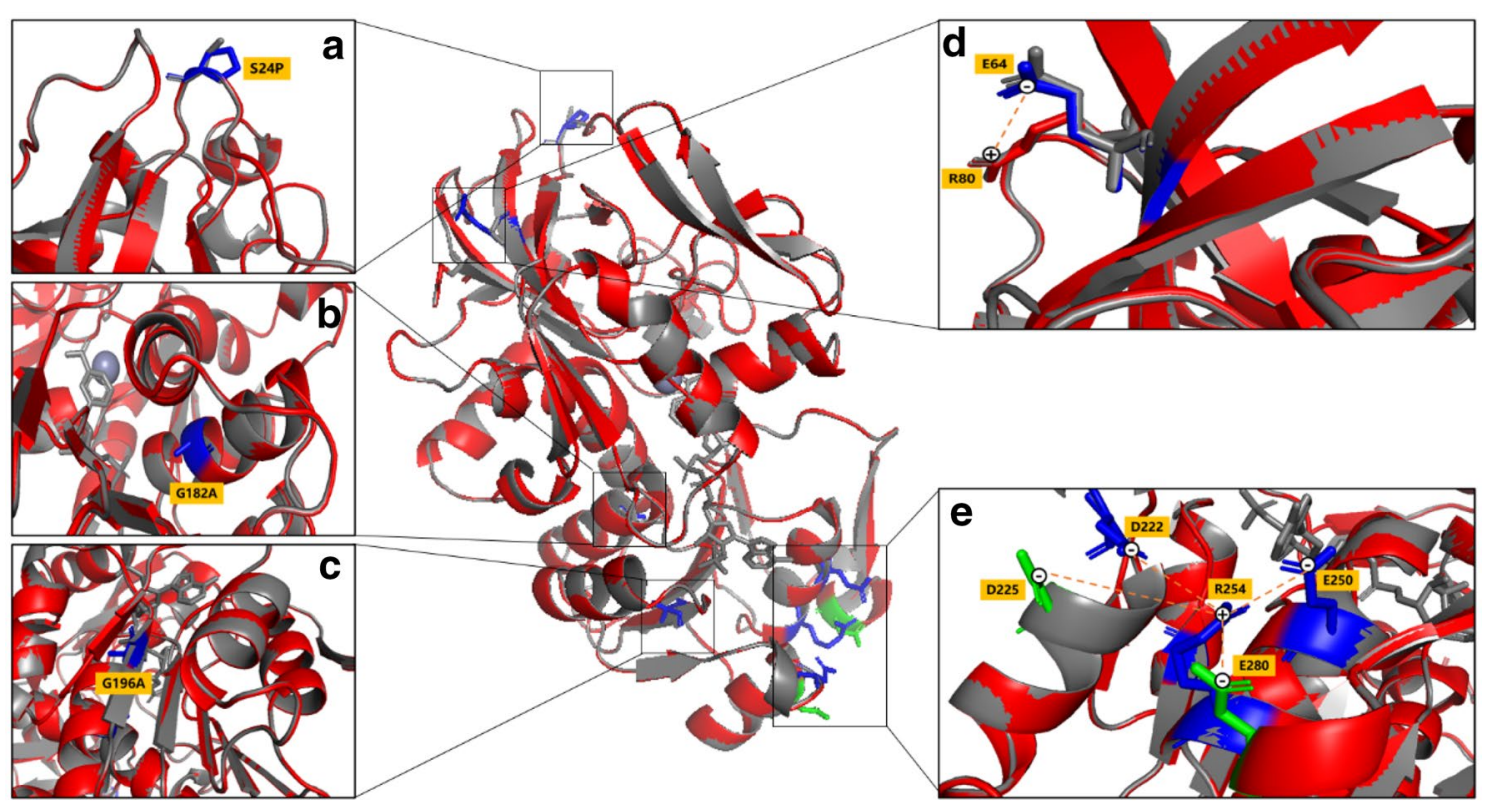

Fig. 5 Protein structure of CbADH-6M (red backbone) compared with the wild CbADH (gray backbone). a The mutant S24P located in the loop region. b The mutant G182A located in the a-helix. c The mutant G196A located at $\beta$-sheets. $\mathbf{d}$ New salt bridge Glu64-Arg80 formed by CbADH-6M. e Schematic diagram of new salt bridge network centered on Arg254

applicable method for computational design of stable and soluble biocatalysts.

\section{Molecular structure analysis of CbADH-6M}

Multiple superimposable mutations can improve the conformational stability of the protein in its natural state, allowing it to gain an advantage in the competition with other misfolded or partially folded states in folding dynamics. Six mutations, S24P, G182A, G196A, H222D, S250E and S254R were introduced into the CbADH-6M mutant. Among the 6 mutation sites involved in CbADH$6 \mathrm{M}$, four sites including 24, 222, 250 and 254 were located on the surface of the protein (Fig. 5). Three mutations including H222D, S250E, and S254R replaced the original amino acid residues with more polar amino acid residues which enhanced the surface polarity. In addition, the significant increase of $T_{1 / 2}^{60 \mathrm{~min}}$ gained by the substitution of Pro for Gln100 in $\mathrm{CbADH}\left(\triangle T_{1 / 2}^{60 \mathrm{~min}}=+8{ }^{\circ} \mathrm{C}\right)$ (Musil et al. 2018) suggested that the proline residue stabilized the protein by reducing the flexibility of a loop at this strategic region. Similarly, when S24 located in a surface loop of the protein was mutated to a proline residue that adopted only a limited number of conformations, the flexibility of the loop was reduced thus rigidifying the protein structure. As to the G182 located in the internal structure of an alpha helix, it was substituted by alanine residue (López-Llano et al. 2006), which is regarded as the most stabilizing residue in internal helical position, whereas glycine is the more destabilizing after proline. Furthermore, it was found that the number of salt bridges in CbADH-6M changed a lot. Although the Asp225His222 salt bridge in the original protein CbADH-WT disappeared due to the amino acid substitution H222D, the replacement of H222D, S250E and S254R led to the formation of four new salt bridges including Arg254Glu250, Arg254-Asp225, Arg254-Glu280 and Arg254Asp222, which constituted a salt bridge network centered on Arg254. Moreover, the angle of the Arg80 changed, making it closer to the Glu60 to form a new salt bridge between Glu64 and Arg80.

\section{Large-scale production of $\mathrm{CbADH}-6 \mathrm{M}$}

In a two-phase high cell density fermentation, the dissolved oxygen dropped sharply in $5 \mathrm{~h}$, and the agitation rate increased at the same time. The other fermentation parameters are shown in Fig. 6a. Sampling was started at 

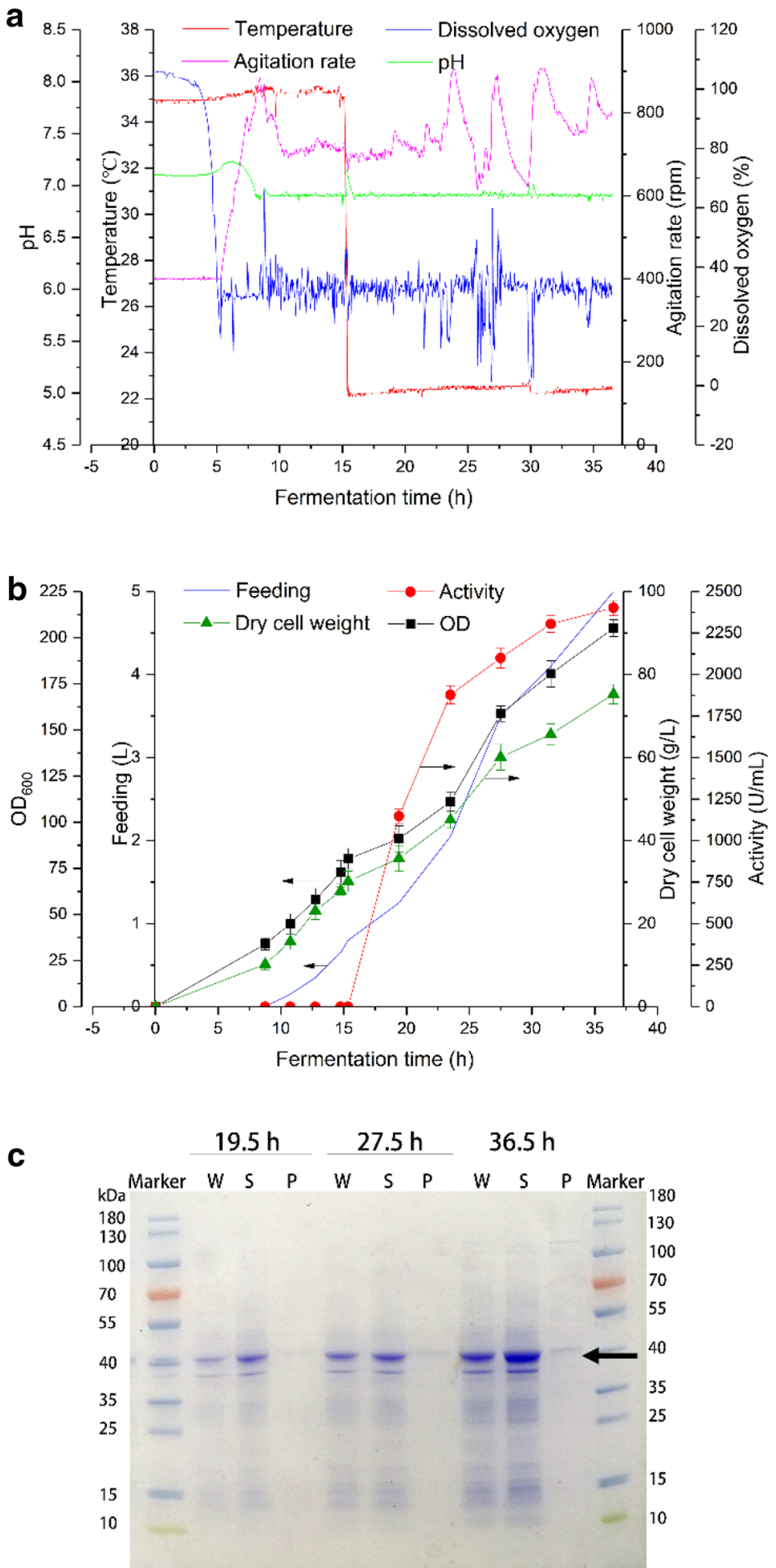

Fig. 6 Fermentation process of recombinant Escherichia coli-pET-28a-CbADH-6M in a 15.0-L mechanically stirred fermentor. a Fermentation parameter control. b Cell growth and CbADH-6M expression during the fermentation. $\mathbf{c}$ SDS-PAGE analysis of protein expression of samples at different time: Lane M: molecular weight marker; Lane W: whole cell protein; Lane S: supernatant; Lane P: precipitation 

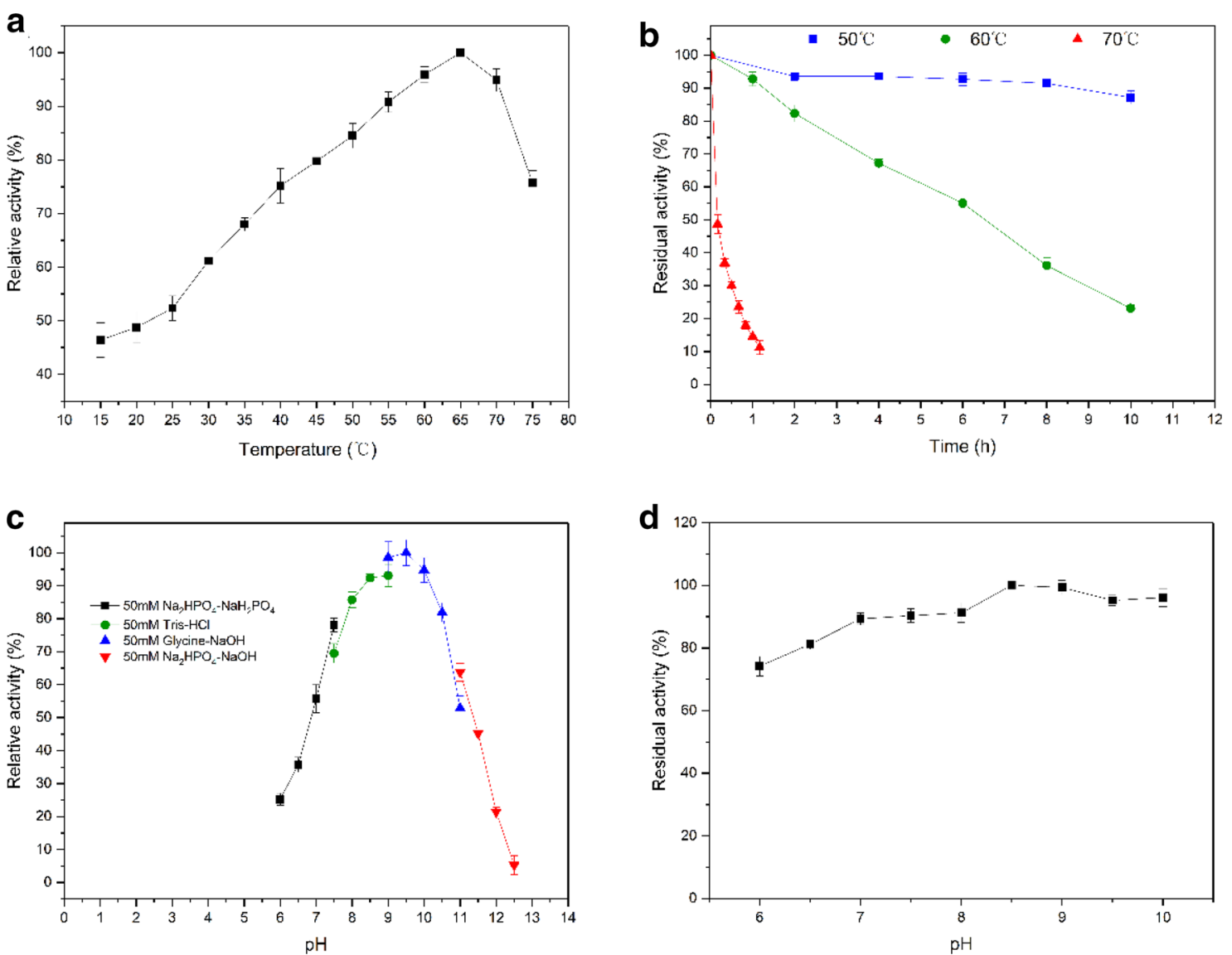

Fig. 7 Characterization of the recombinant $\mathrm{CbADH}-6 \mathrm{M}$. a Temperature optimum: the enzyme activity was measured at various temperatures $\left(15-75^{\circ} \mathrm{C}\right)$ in phosphate buffer $(\mathrm{pH} 7.5)$. b Thermostability: $1.0 \mathrm{\mu g} / \mathrm{mL}$ purified enzyme was incubated at the specific temperature $(50,60,70)$ for different times, and the residual activity was measured by standard assay. $\mathbf{c ~ p H}$ optimum: the enzyme activity was assayed in various buffers (6.0-12.5) at $35^{\circ} \mathrm{C} . \mathbf{d} \mathrm{pH}$ stability: $\mathrm{pH}$ stability was measured by incubation of purified enzyme in different buffers (pH $\left.6-10\right)$ for $24 \mathrm{~h}$ at $35^{\circ} \mathrm{C}$, and the residual activity was measured by standard assay

$9 \mathrm{~h}$, and the measured $\mathrm{OD}_{600}$ reached 80.1 at $15 \mathrm{~h}$, and the induction temperature was $22{ }^{\circ} \mathrm{C}$. During the subsequent fed fermentation, glycerol was used as carbon source instead of glucose, the utilization of which by $E$. coli cells was faster and more complete. Moreover, the accumulation of acetic acid in the process was effectively controlled near zero by the feeding strategy of dissolved oxygen feedback, so the main inhibiting factor of the growth of E. coli cells was eliminated and the enzyme activity and $\mathrm{OD}_{600}$ could increase steadily (Fig. $6 \mathrm{~b}$ ). At the end of the fermentation $(36.5 \mathrm{~h})$, the $\mathrm{OD}_{600}$ reached 205.2 and the enzyme activity reached $2401.8 \mathrm{U} / \mathrm{mL}$ (31.9 U/mg dcw). As shown in the SDS-PAGE, the sampling was carried out at $19.5 \mathrm{~h}, 27.5 \mathrm{~h}$ and $36.5 \mathrm{~h}$ and the amount of total protein and soluble protein continued to increase as the fermentation proceeded. And almost no precipitation was observed indicating the excellent soluble expression achieved (Fig. 6c). 
a
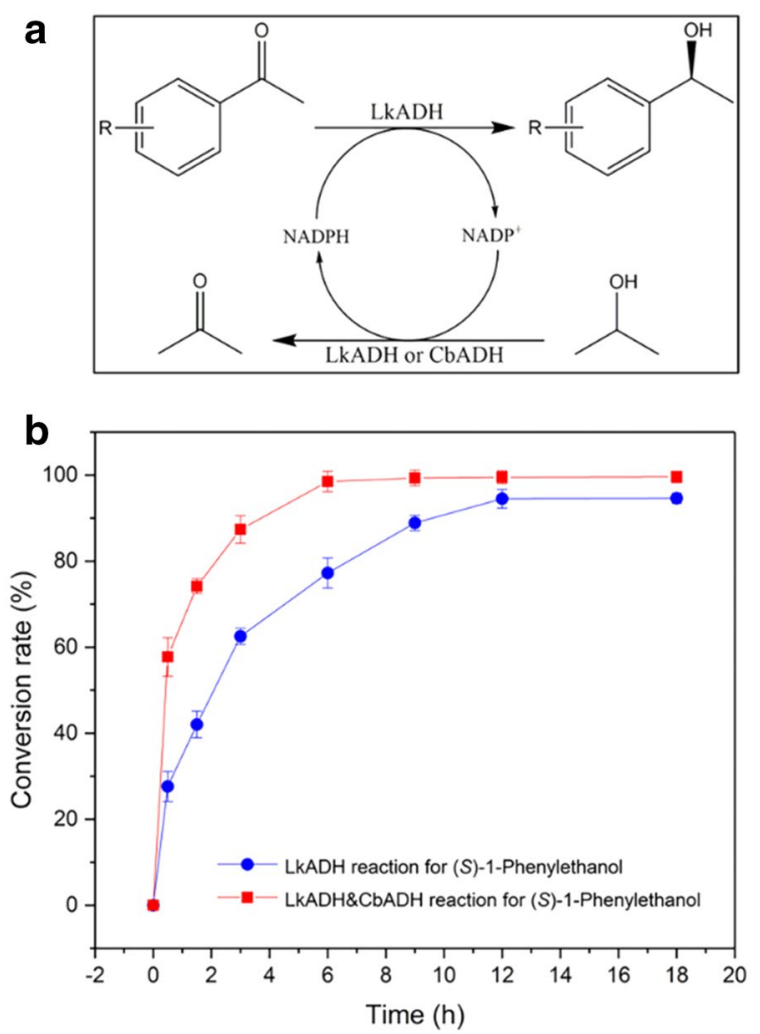

Fig. 8 The reduction of acetophenone for synthesis of (S)-1-phenylethanol. a LkADH mono-enzymatic reaction. $\mathbf{b} \mathrm{LkADH}$ and $\mathrm{CbADH}(\mathrm{CbADH}-6 \mathrm{M})$ dual enzyme catalyzed reaction

\section{Biochemical characterization of recombinant CbADH-6M}

The recombinant $\mathrm{CbADH}-6 \mathrm{M}$ was purified and the specific activity was detected to be $148 \pm 1.5 \mathrm{U} / \mathrm{mg}$ at standard condition $\left(35^{\circ} \mathrm{C}\right.$ and $\left.\mathrm{pH} 7.5\right)$, which was slightly lower than the wild type. Then the activity of purified CbADH$6 \mathrm{M}$ was measured at various temperatures ranging from 15 to $75^{\circ} \mathrm{C}$. As the temperature increased, the enzyme activity increased constantly, reaching the highest at $65^{\circ} \mathrm{C}$ (Fig. 7a). Thermostability of the purified CbADH-6M was investigated at temperatures of 50, 60 and $70{ }^{\circ} \mathrm{C}$ (Fig. 7b), and the half-lives of the recombinant enzyme were measured to be $62.4 \mathrm{~h}, 4.9 \mathrm{~h}$ and $0.4 \mathrm{~h}$ (Additional file 1: Table S5), respectively. The optimum $\mathrm{pH}$ was determined by measuring the enzyme activities at different $\mathrm{pH}$ from 6.0-13.0 (Fig. 7c). The maximum activity was observed at $\mathrm{pH}$ of 9.5 (glycine- $\mathrm{NaOH}$ buffer). Investigation of $\mathrm{pH}$ stability showed that $\mathrm{CbADH}-6 \mathrm{M}$ remained relatively high activity from $\mathrm{pH} 6.0$ to $\mathrm{pH} 10.0$ (Fig. 7d).

\section{Regeneration of NADPH using recombinant CbADH-6M}

To explore the potential of $\mathrm{CbADH}$ at in situ NADPH regeneration, an engineered $\mathrm{ADH}$ from Lactobacillus kefir LkADH (He et al. 2015) coupled with CbADH$6 \mathrm{M}$ was employed in the synthesis of several fine chiral aromatic alcohols (Fig. 8a and Table 1). As shown in the reduction reaction for the synthesis of (S)-1-phenylethanol, if only LKADH was used, the reaction rate was low, and the conversion rate (Fig. 8b) hardly reached $100 \%$. However, when the $\mathrm{CbADH}$ was added for the coenzyme recycle, the catalytic rate greatly accelerated. Additionally, in contrast to the reaction system catalyzed only by LkADH, the conversion rate of $\mathrm{LkADH}$ and $\mathrm{CbADH}$ reaction reached $100 \%$ within $6 \mathrm{~h}$. Not only in the production of (S)-1-phenylethanol, but also in the synthesis of other important chiral aromatic alcohols (Table 1), reactions catalyzed by LkADH and $\mathrm{CbADH}$ exhibited much higher conversion rate than the LkADH mono-enzymatic reactions, indicating the great potential of $\mathrm{CbADH}-6 \mathrm{M}$ in industrial applications.

\section{Conclusions}

In summary, $\mathrm{CbADH}$ with high stability and specific activity was identified for NADPH regeneration and a computational protein design named PROSS was applied for the soluble modification of this enzyme. The multipoint mutant $\mathrm{CbADH}-6 \mathrm{M}$ displayed a superb solubility and recombinant expression level than the wild type, with an enzyme activity of $46.3 \mathrm{U} / \mathrm{mL}, 16$-fold improvement compared to the wild type in shake-flask fermentation and $2401.8 \mathrm{U} / \mathrm{mL}$ in two-phase high cell density fermentation. Additionally, the combining effect of multiple mutations in the variant improved the conformational stability of this protein, as well as the thermal stability. When coupling CbADH-6M (only 5\% of total enzyme dosage) with LkADH, the catalytic rate of the reduction was greatly improved and the conversion rate was significantly higher than the reactions catalyzed by LkADH. The ee value of the product in the final reaction mixture was larger than $99 \%$, showing a strict stereoselectivity. This CbADH-6M could be potentially used for the NADPH regeneration in the industrial synthesis of valuable compounds. 
Xu et al. Bioresour. Bioprocess. $\quad$ (2021) 8:12

Page 11 of 13

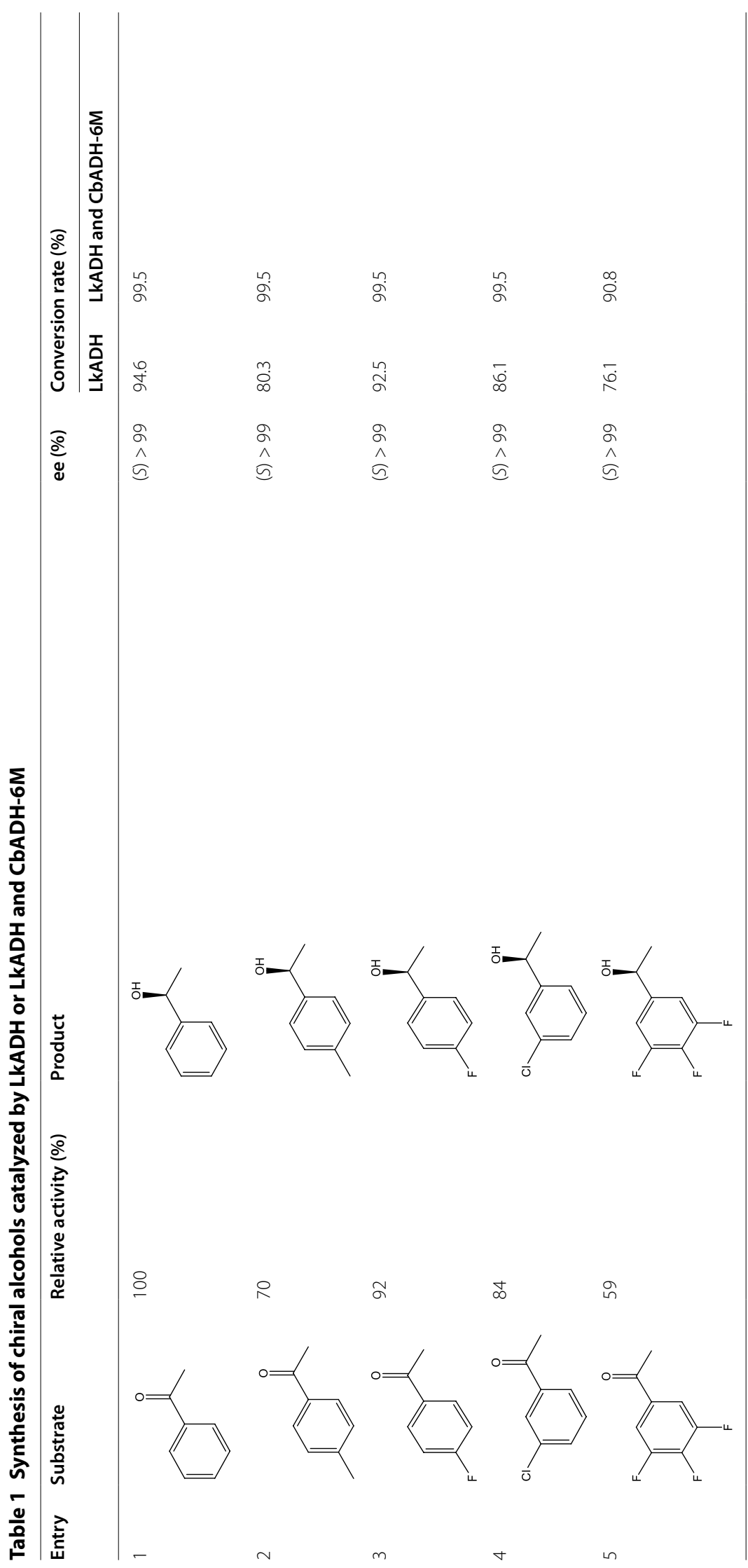




\section{Supplementary Information}

The online version contains supplementary material available at https://doi. org/10.1186/s40643-021-00362-w.

Additional file 1: Table S1. Information of NADPH-dependent alcoho dehydrogenase. Table S2. Information of selected alcohol dehydrogenase. Table S3. The mutation sites of the PROSS mutants. Table S4. Thermal stability of the recombinant LkADH. Table S5. Activity half-life of the recombinant $\mathrm{CbADH}-6 \mathrm{M}$. Figure $\mathbf{S 1}$. Multiple sequence alignment of alcohol dehydrogenases. Figure S2. SDS-PAGE analysis of the protein expression of the alcohol dehydrogenases. Figure S3. SDS-PAGE analysis of the protein expression at different inducing temperatures. Figure $\mathbf{S 4}$. SDS-PAGE analysis of the protein expression at different IPTG concentration. Figure S5. CbADH activity of molecular chaperones co-expression strains. Fig S6. SDS-PAGE analysis of protein expression of molecular chaperones co-expression strains. Fig S7. Multiple sequence alignment of CbADH mutant. Fig S8. SDS-PAGE analysis of protein expression of PROSS mutants. Fig S9. Protein purification of PROSS mutants. Fig S10 HPLC spectrum of (S)-1-phenylethanol. Fig S11. HPLC spectrum of (S)-1-(4methylphenyl)ethanol. Fig S12. HPLC spectrum of (S)-1-(4-fluorophenyl) ethanol. Fig S13. HPLC spectrum of (S)-1-(4-chlorophenyl)ethanol. Fig S14. HPLC spectrum of (S)-1-(3,4,5-trifluorophenyl)ethanol.

\section{Abbreviations}

ADH: Alcohol dehydrogenase; $\mathrm{CbADH}$ : An alcohol dehydrogenase from Clostridium beijerinckii; LkADH: An alcohol dehydrogenase from Lactobacillus kefir; WT: Wild type; HPLC: High-performance liquid chromatography.

\section{Acknowledgements \\ Not applicable.}

\section{Authors' contributions}

YLR designed the concept of this study. XJL, DT and ZHS carried out the experimental procedures. XJL and ZHS analyzed the result and drafted the manuscript. ZHS and YHR provided ideas for writing and revised the manuscript. WZY, ZHY and WJP provided experimental assistance and helped revise writing. All authors read and approved the final manuscript.

\section{Funding}

This work was financially supported by National Key R\&D Program of China (No. 2019YFA09005000) and National Natural Science Foundation of China (No. 21476199).

\section{Availability of data and materials}

The data and materials in this work are available from the corresponding author on reasonable request.

\section{Ethics approval and consent to participate}

Not applicable.

\section{Consent for publication}

All authors approved the consent for publishing the manuscript to Bioresources and Bioprocessing.

\section{Competing interests}

The authors declare that they have no competing interests.

Received: 2 November 2020 Accepted: 19 January 2021

Published online: 07 February 2021

\section{References}

Balbás P (2001) Understanding the art of producing protein and nonprotein molecules in Escherichia coli. Mol Biotechnol 19(3):251-267

Bastos FDM, dos Santos AG, Jones J, Oestreicher EG, Pinto GF, Paiva LMC (1999) Three different coupled enzymatic systems for in situ regeneration of NADPH. Biotechnol Techniques 13(10):661-664
Benítez-Mateos Al, San Sebastian E, Ríos-Lombardía N, Morís F, González-Sabín J, López-Gallego F (2017) Asymmetric reduction of prochiral ketones by using self-sufficient heterogeneous biocatalysts based on NADPHDependent Ketoreductases. Chem Eur J 23(66):16843-16852

Bogin O, Levin I, Hacham Y, Tel-Or S, Peretz M, Frolow F, Burstein Y (2002) Structural basis for the enhanced thermal stability of alcohol dehydrogenase mutants from the mesophilic bacterium Clostridium beijerinckii: contribution of salt bridging. Protein Sci 11(11):2561-2574

Brown KA, Wilker MB, Boehm M, Hamby H, Dukovic G, King PW (2016) Photocatalytic regeneration of nicotinamide cofactors by quantum dotenzyme biohybrid complexes. ACS Catalysis 6(4):2201-2204

Carugo O, Argos P (1997) NADP-dependent enzymes. I: conserved stereochemistry of cofactor binding. . Proteins Struct Funct Genetics 28:10-28

Celik A, Ates SC, Can H, Kusku S, Erol I (2014) Protein engineering of FDHs for cofactor $(\mathrm{NAD}(\mathrm{P}) \mathrm{H})$ recycling in reactions catalysed by oxidoreductases. J Biotechnol 185:S19-S20

Deng T, Zhou HS, Wu JP, Yang LR (2020) Enhance soluble heteroexpression of a NADPH-dependent alcohol dehydrogenase based on the chaperone strategy. China Biotechnol 40(8):24-32

Ding HT, Du YQ, Liu DF, Li ZL, Chen XJ, Zhao YH (2011) Cloning and expression in E. coli of an organic solvent-tolerant and alkali-resistant glucose 1-dehydrogenase from Lysinibacillus sphaericus G10. Bioresour Technol 102(2):1528-1536

Donovan RS, Robinson CW, Glick BR (1996) Review: optimizing inducer and culture conditions for expression of foreign proteins under the control of the lac promoter. J Ind Microbiol 16(3):145-154

Fan Q, Neubauer P, Lenz O, Gimpel M (2020) Heterologous hydrogenase overproduction systems for biotechnology —an overview. Int J Mol Sci 21(16):5890

Fukuzumi S, Lee Y-M, Nam W (2019) Catalytic recycling of NAD(P)H. J Inorganic Biochem 199:110777

Goihberg E, Dym O, Tel-Or S, Levin I, Peretz M, Burstein Y (2007) A single proline substitution is critical for the thermostabilization of Clostridium beijerinckii alcohol dehydrogenase. Proteins-Struct Funct Bioinformat 66(1):196-204

Goldenzweig A, Goldsmith M, Hill SE, Gertman O, Laurino P, Ashani Y, Dym O, Unger T, Albeck S, Prilusky J, Lieberman RL, Aharoni A, Silman I, Sussman JL, Tawfik DS, Fleishman SJ (2016) Automated structure- and sequencebased design of proteins for high bacterial expression and stability. Mol Cell 63(2):337-346

He XJ, Chen SY, Wu JP, Yang LR, Xu G (2015) Highly efficient enzymatic synthesis of tert-butyl (S)-6-chloro-5-hydroxy-3-oxohexanoate with a mutant alcohol dehydrogenase of Lactobacillus kefir. Appl Microbiol Biotechnol 99(21):8963-8975

Huisman GW, Liang J, Krebber A (2010) Practical chiral alcohol manufacture using ketoreductases. Curr Opin Chem Biol 14(2):122-129

Itoh N (2014) Use of the anti-Prelog stereospecific alcohol dehydrogenase from Leifsonia and Pseudomonas for producing chiral alcohols. Appl Microbiol Biotechnol 98(9):3889-3904

Johannes TW, Woodyer RD, Zhao H (2007a) Efficient regeneration of NADPH using an engineered phosphite dehydrogenase. Biotechnol Bioeng 96(1):18-26

Landwehr M, Hochrein L, Otey CR, Kasrayan A, Bäckvall J-E, Arnold FH (2006) Enantioselective a-Hydroxylation of 2-Arylacetic acid derivatives and buspirone catalyzed by engineered cytochrome P450 BM-3. J Am Chem Soc 128(18):6058-6059

Liu W, Wang P (2007) Cofactor regeneration for sustainable enzymatic biosynthesis. Biotechnol Adv 25(4):369-384

López-Llano J, Campos LA, Sancho J (2006) a-helix stabilization by alanine relative to glycine: roles of polar and apolar solvent exposures and of backbone entropy. Proteins Struct Funct Bioinf 64:769-778

Mori S, Pang AH, Thamban Chandrika N, Garneau-Tsodikova S, Tsodikov OV (2019) Unusual substrate and halide versatility of phenolic halogenase PItM. Nat Communicat 10(1):1

Musil M, Konegger H, Hon J, Bednar D, Damborsky J (2018) Computational design of stable and soluble biocatalysts. ACS Catalysis 9(2):1033-1054

Peretz M, Bogin O, Tel-Or S, Cohen A, Li G, Chen J-S, Burstein Y (1997) Molecular cloning, nucleotide sequencing, and expression of genes encoding alcohol dehydrogenases from the ThermophileThermoanaerobacter brockii and the Mesophile Clostridium beijerinckii. Anaerobe 3(4):259-270 
Schmidt S, Scherkus C, Muschiol J, Menyes U, Winkler T, Hummel W, Gröger H, Liese A, Herz H-G, Bornscheuer UT (2015) An enzyme cascade synthesis of $\varepsilon$-caprolactone and its oligomers. Angew Chem Int Ed 54(9):2784-2787

Straathof AJJ, Panke S, Schmid A (2002) The production of fine chemicals by biotransformations. Curr Opin Biotechnol 13(6):548-556

Vázquez-Figueroa E, Chaparro-Riggers J, Bommarius AS (2007) Development of a thermostable glucose dehydrogenase by a structure-guided consensus concept. ChemBioChem 8(18):2295-2301

Weckbecker A, Hummel W (2005) Glucose Dehydrogenase for the Regeneration of NADPH and NADH. In: Barredo JL (ed) Microbial Enzymes and Biotransformations. Humana Press. Totowa, NJ, pp 225-238

Wennekes LM, Goosen T, Fau-van den Broek PJ, van den Broek PJ, Fau-van den Broek HW, van den Broek HW (1993) Purification and characterization of glucose-6-phosphate dehydrogenase from Aspergillus niger and Aspergillus nidulans. J General Microbiol 139(0022-1287):2793-2800

Wichmann R, Vasic-Racki D (2005) Cofactor regeneration at the lab scale. Adv Biochem Eng Biotechnol 92:225-260

Widdel F, Wolfe RS (1989) Expression of secondary alcohol dehydrogenase in methanogenic bacteria and purification of the F420-specific enzyme from Methanogenium thermophilum strain TCl. Arch Microbiol 152(4):322-328

Woodyer R, Zhao H, Van Der Donk WA (2005) Mechanistic investigation of a highly active phosphite dehydrogenase mutant and its application for NADPH regeneration. FEBS J 272(15):3816-3827

Yin X, Liu Y, Meng L, Zhou H, Wu J, Yang L (2020) Semi-rational hinge engineering: modulating the conformational transformation of glutamate dehydrogenase for enhanced reductive amination activity towards nonnatural substrates. Catal Sci Technol 10(10):3376-3386

Zhang J, Witholt B, Li Z (2006) Efficient NADPH Recycling in enantioselective bioreduction of a ketone with permeabilized cells of a microorganism containing a ketoreductase and a glucose 6-phosphate dehydrogenase. Adv Synth Catal 348(4-5):429-433

Zhu D, Hua L (2006) Enantioselective Enzymatic Reductions of sterically bulky aryl alkyl ketones catalyzed by a NADPH-dependent carbonyl reductase. J Organic Chem 71(25):9484-9486

\section{Publisher's Note}

Springer Nature remains neutral with regard to jurisdictional claims in published maps and institutional affiliations.

\section{Submit your manuscript to a SpringerOpen ${ }^{\circ}$ journal and benefit from:}

- Convenient online submission

- Rigorous peer review

- Open access: articles freely available online

- High visibility within the field

- Retaining the copyright to your article

Submit your next manuscript at $\boldsymbol{\nabla}$ springeropen.com 